\title{
Air pressure effects on biomass yield of two different Kluyveromyces strains
}

\author{
R. Pinheiro, I. Belo, M. Mota* \\ Centre of Biological Engineering, IBQF, University of Minho, 4700 Braga Portugal
}

Received 24 March 1999; received in revised form 20 December 1999; accepted 18 January 2000

\begin{abstract}
The use of air pressure as a way of improving oxygen transfer in aerobic bioreactors was investigated. To compare the air pressure effects with traditional air bubbled cultures, experiments using a pressure reactor and a stirred flask, with the same oxygen transfer rate, were made. Kluyveromyces marxianus is an important industrial yeast and some of it show a "Kluyver effect" for lactose: even under oxygen limited growth conditions, certain disaccharides that support aerobic, respiratory growth, are not fermented. This study deals with the effect of increased pressure on the physiological behavior of two Kluyveromyces strains: K. marxianus ATCC10022 is a lactose-fermenting strain, whereas K. marxianus CBS 7894 has a Kluyver-effect for lactose. For K. marxianus ATCC10022 an air pressure increase of 2 bar led to a 3-fold increase in biomass yield. When air pressure increased an enhancement of ethanol oxidation of cell yeasts was also observed. Batch cultures of $K$. marxianus CBS 7894 exhibited different growth behaviour. Its metabolism was always oxidative and ethanol was never produced. With the increase in air pressure, it was possible to increase the productivity in biomass of $K$. marxianus CBS 7894 . As a response to high oxygen concentrations, due to the increase in oxygen partial pressure, oxidative stress in the cells was also studied. Antioxidant defences, such as superoxide dismutase, catalase, and glutathione reductase, were at high activity levels, suggesting that these yeast strains could tolerate the increased pressures applied. (C) 2000 Elsevier Science Inc. All rights reserved.
\end{abstract}

Keywords: Pressure; Kluyveromyces; Yield; Growth; Oxidative stress

\section{Introduction}

In the past decade, yeasts other than Saccharomyces cerevisiae have gained industrial interest as hosts for heterologous protein production. Examples are methanol-utilising yeasts such as Hansenula polymorpha and Pichia pastoris and the lactose-utilizing species Kluyveromyces lactis and marxianus (e.g. $\beta$-galactosidase and biomass production) [1-3]. It is accepted that the application of these yeasts in large scale fermentations for the production of heterologous proteins will be probably a common industrial practice by the end of this century [1]. Several Kluyveromyces strains have been reported to exhibit a "Kluyver effect" for lactose: even under oxygen-limited growth conditions, certain disaccharides that support aerobic, respiratory growth, are not fermented [4]. There are also other Kluyveromyces strains, which are lactose fermentative, "Kluyver-negative"

\footnotetext{
* Corresponding author. Tel.: +00351-53-604400; fax: +00351-53604413.

E-mail address: rita@ci.uminho.pt (R. Pinheiro).
}

yeasts. It is important to establish the differences between these two yeasts from the point of view of both their biotechnological applications and the basic research in metabolism and gene regulation [3].

In typical Kluyveromyces cultivation, quite high cell densities are reached and oxygen is usually the major growth limiting factor [5]. The use of pressure into bioreactors can be a way of eliminating this limitation. The traditional way of improving oxygen transfer rate, that is, increasing stirring rate, has several limitations, such as power consumption and cell damage, due to mechanical effects [6].

Oxygen, however, may have toxic effects on aerobic microorganisms, a phenomenon known as oxidative stress. During the reduction of molecular oxygen to water through acceptance of four electrons, active oxygen species such as superoxide anion radical $\left(\mathrm{O}_{2} \cdot{ }^{\cdot}\right)$, hydrogen peroxide $\left(\mathrm{H}_{2} \mathrm{O}_{2}\right)$, and hydroxyl radical (HO·) are generated. These active oxygen species may give rise to damage of enzymes, nucleic acids, or lipids [7]. As a safeguard against these radicals, aerobic organisms have developed enzymes, antioxidant enzymes, which are able to transform these reactive 
oxygen species into nonreactive ones. The more important antioxidant enzymes are the cytosolic and mitochondrial superoxide dismutase, glutathione reductase, and catalase [8-11].

The increase in air pressure leads to the consequent increase in oxygen partial pressure, and toxic effects may occur if oxygen concentration is high [8]. Biomass yield on carbohydrate feedstock is a key optimization criterion for production of yeast biomass or (heterologous) proteins. Alcoholic fermentation has to be avoided in such processes because biomass yields during fermentative growth are much lower than those during oxidative metabolism [2]. The aim of this work is to investigate whether increasing air pressures (increasing oxygen transfer rate) may lead to increasing biomass yields, and productivities in both Kluyveromyces species, without giving rise to oxidative stress.

\section{Materials and methods}

\subsection{Strains}

Two Kluyveromyces marxianus strains, ATCC10022 ("Kluyver-negative") and CBS 7894 ("Kluyver-positive") were used.

\subsection{Media}

The mineral medium consisted of $5 \mathrm{~g} \mathrm{KH}_{2} \mathrm{PO}_{4} / \mathrm{l}, 1.2 \mathrm{~g}$ $\left(\mathrm{NH}_{4}\right) \mathrm{SO}_{4} / 1,0.4 \mathrm{~g} \mathrm{MgSO}_{4} \cdot 7 \mathrm{H}_{2} \mathrm{O} / \mathrm{l}$, and $1 \mathrm{~g}$ yeast extract/l in a potassium phosphate buffer $0.2 \mathrm{M}$, pH 5.5. Lactose was used as the main carbon source at three different concentrations, 20, 40, and $100 \mathrm{~g} / \mathrm{l}$, except that in $K$. marxianus CBS 7894, only two concentrations, 10 and 40 g/l, were used. In all the experiments, the temperature was maintained at $30^{\circ} \mathrm{C}$.

\subsection{Operating conditions}

Yeast cells were pregrown in 250-ml Erlenmeyer flasks on $10 \%$ of the experiment total volume of the mineral medium described above, containing $2 \mathrm{~g}$ lactose/l. Batch cultivations took place with three different operating conditions: under pressure, micro aerated, and air bubble experiments.

\subsubsection{Pressure experiments}

Batch cultivations were carried out using a cylindrical stainless steel pressure reactor with a total volume of 300 $\mathrm{ml}$. The working volume was $150 \mathrm{ml}$ and the agitation speed $150 \mathrm{rpm}$. The air was fed continuously into the bioreactor headspace at $1 \mathrm{vvm}$ of aeration rate. Three different air pressures, 2, 4, and 6 bar, were investigated.
Table 1

Oxygen transfer rate (OTR) for each experiment made with pressure (pressure reactor) and with air-bubble (stirred flask). These values were determined using the sulphite oxidation method.

\begin{tabular}{lcccc}
\hline Air pressure (bar) & 2 & 4 & 6 & $\begin{array}{c}330 \mathrm{rpm}+1 \\
\text { vvm air }\end{array}$ \\
$\begin{array}{l}\text { OTR (mg O} / \mathrm{lh}) \\
\text { (value } \pm \text { standard error) }\end{array}$ & $365 \pm 41$ & $806 \pm 89$ & $1099 \pm 62$ & $429 \pm 179$ \\
\hline
\end{tabular}

\subsubsection{Micro aerated experiments}

Batch cultivations were made in an orbital shaker under atmospheric pressure (1 bar), without air introduction at an agitation of $150 \mathrm{rpm}$. These experiments were run in parallel with the others to be used as a control.

\subsubsection{Air-bubble experiments}

Batch cultivations were made in stirred flask (bladestirrer) under atmospheric pressure (1 bar) with air bubbling into the culture at an air flow rate of $1 \mathrm{vvm}$, using a stirring speed of $330 \mathrm{rpm}$. These experiments were done with a higher stirring rate than the pressurized experiments in order to have a similar OTR $(429 \pm 179 \mathrm{mg} / \mathrm{Lh})$ as with the 2-bar air pressure experiment. These operating conditions made possible compare which condition would give better results.

\subsection{Determination of oxygen transfer rate (OTR)}

The oxygen transfer rate (OTR) in the pressurized reactor and in the stirred flask was measured using the sulphite oxidation method in blank assays. This method is based on the oxidation of sodium sulphite $(0.2 \mathrm{M})$ to sulphate in the presence of a catalyst, which was in this case, $\mathrm{Cu}^{2+}(0.001$ M). Samples of the solution are collected at regular intervals and the concentration of unreacted sulphite is determined by reacting the sulphite in each sample with excess iodine $(0.05$ $\mathrm{M})$. The rate of oxygen transfer is proportional to the decrease of sulphite (Table 1).

\subsection{Analytical methods}

At appropriate intervals, culture samples were collected for analysis of cell dry weight, ATP, lactose and ethanol concentrations, and for enzymatic assays. Growth was measured by optical density at $620 \mathrm{~nm}$, and converted to g cell dry weight/l (g CDW/l or biomass). Glucose was determined using the 3,5-dinitrosalycilic acid (DNS) method [12]. Ethanol was detected by HPLC analysis. The column was eluted at $60^{\circ} \mathrm{C}$ with $0.01 \mathrm{~N} \mathrm{H} 2 \mathrm{SO} 4$ at a flow rate of 0.75 $\mathrm{ml} / \mathrm{min}$. Detection was made with a refractive index (RI). The quantity of ATP present in a biomass sample was determined using the bioluminescence method according to Siro et al. [13]. The ATP was initially extracted from the cells with an appropriate extracting reagent, and then reacted with luciferin in a reaction catalyzed by the enzyme luciferase. One of the reaction products is luminescence, 
which is measured using a bioluminometer. The light transmission is proportional to the concentration of cellular ATP. The specific ATP concentration (g CDW/mgATP) was determined by the ratio of cell concentration $(\mathrm{gCDW} / \mathrm{l})$ and ATP concentration $(\mathrm{mgATP} / \mathrm{ml})$ for each sample taken. Protein in cell extracts was measured using the coomassie blue method [14]. Bovine serum albumin was used as a standard.

\subsection{Preparations of cell extracts}

Cells were harvested from the cultures by centrifugation $(5000 \times g, 10 \mathrm{~min}$.), washed once with $50 \mathrm{mM}$ potassium phosphate buffer ( $\mathrm{pH}$ 7.8) containing $1 \mathrm{mM}$ EDTA and resuspended in the same buffer, frozen, and stored at $-20^{\circ} \mathrm{C}$. Cells were disrupted by mechanical disruption with 0.5 - $\mathrm{mm}$ glass beads during $6 \mathrm{~min}(1 \mathrm{~min}$ bursts with $1 \mathrm{~min}$ cooling intervals). Whole cells and debris were removed by centrifugation at $5000 \times g$ for $15 \mathrm{~min}$ at $4^{\circ} \mathrm{C}$. The clear supernatant was dialysed overnight.

\subsection{Enzymatic assays}

Enzyme assays were performed after dialysis of the extracts. Superoxide dismutase (SOD) was assayed by the method of McCord and Fridovich [15], mitochondrial superoxide dismutase (Mn-SOD) by the same method but in the presence of $0.6 \mathrm{M} \mathrm{KCN}$, and cytosolic superoxide dismutase (CuZn-SOD) by difference between the two rates. Catalase was assayed using the method described by Beers and Sizer [16] and glutathione reductase was assayed according to Smith et al. [17].

\section{Results and discussion}

\subsection{Pressure effect on "Kluyver-negative" yeast growth}

The effect of increased air pressure as a means of improving oxygen transfer rate in the culture was investigated with different lactose concentrations. In Fig. 1 it is possible to observe that a small increase in air pressure, 2 bar, led to a 3-fold increase in biomass yield, for all lactose concentrations. Further increase in air pressure did not give a significant increase in biomass yield. This Kluyveromyces strain seems to suffer from an inhibitory effect for high lactose concentrations. At $100 \mathrm{~g}$ lactose/l, cells consumed only $30 \%$ of the initial lactose concentration and no further consumption was detected. However, with low lactose concentrations, this strain metabolized the substrate completely, producing biomass and ethanol. In all the experiments oxidoreductive metabolism was observed, but with the increase in partial oxygen pressure a decrease in ethanol yield was obtained.

The use of air pressure did not cause an inhibitory effect on yeast growth. In turn, Onken [5] reported that in batch cultures of Pseudomonas fluorescens, growth was completely inhibited with 8 bar air pressure. This shows that microorganisms react differently to increased air pressure. Nevertheless, the use of pressure might be exploited to improve the productivities of some microorganisms in industries, especially those that may present a metabolic adaptation of the cells to high oxygen partial pressures [5].

Typical batch growth curves for lactose concentrations of $20 \mathrm{~g} / \mathrm{l}$ and $40 \mathrm{~g} / \mathrm{l}$ were found for this yeast (Fig. 2). In a first phase, cells consumed lactose, which was metabolized oxidoreductively and, in a second phase, ethanol was metabolized oxidatively. On the contrary, in non-pressurized experiments the ethanol produced was not oxidized by cells. Fig. 2 shows the ethanol variation with the pressure: as pressure increased, the ethanol production decreased. Similar results were reported by Pinheiro et al. [18], where pure oxygen and air pressures enhanced ethanol oxidative metabolism on cultures of baker's yeast. The pressure effect on ethanol production was more significant with an initial lactose concentration of $100 \mathrm{~g} / \mathrm{l}$. For a 6-bar air pressure, practically no ethanol was produced, whereas with a low air pressure, 2-bar, a high ethanol concentration was obtained and less biomass produced.
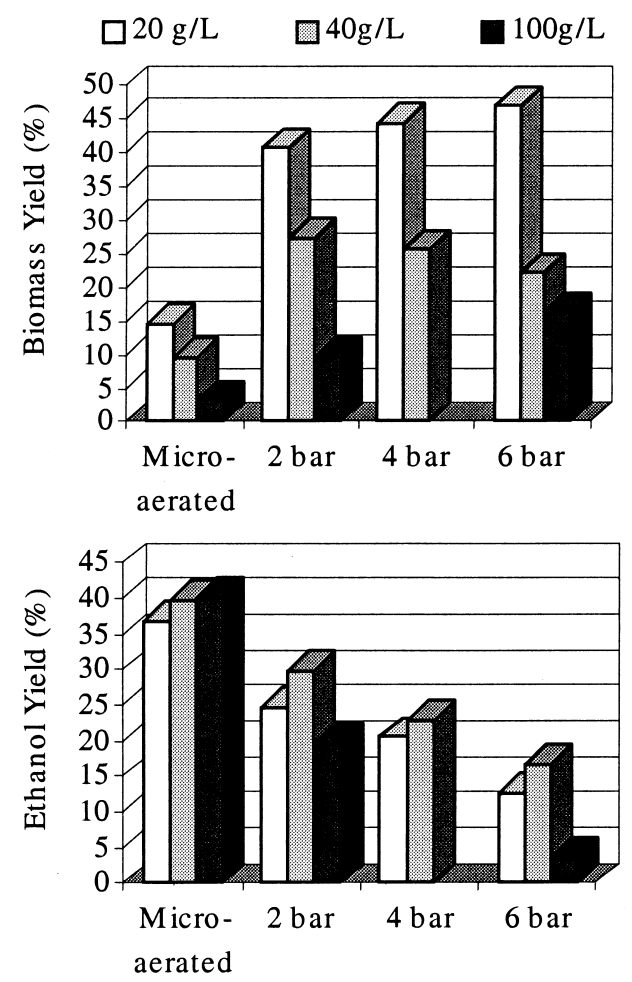

Fig. 1. Effect of air pressure on biomass overall yield (g CDW/g lactose) and ethanol overall yield ( $\mathrm{g}$ ethanol/g lactose) for different lactose concentrations. Percentage of biomass yield was determined by the ratio of the difference between final (maximum) and inicial biomass produced, and the difference between final and inicial lactose consumed. 

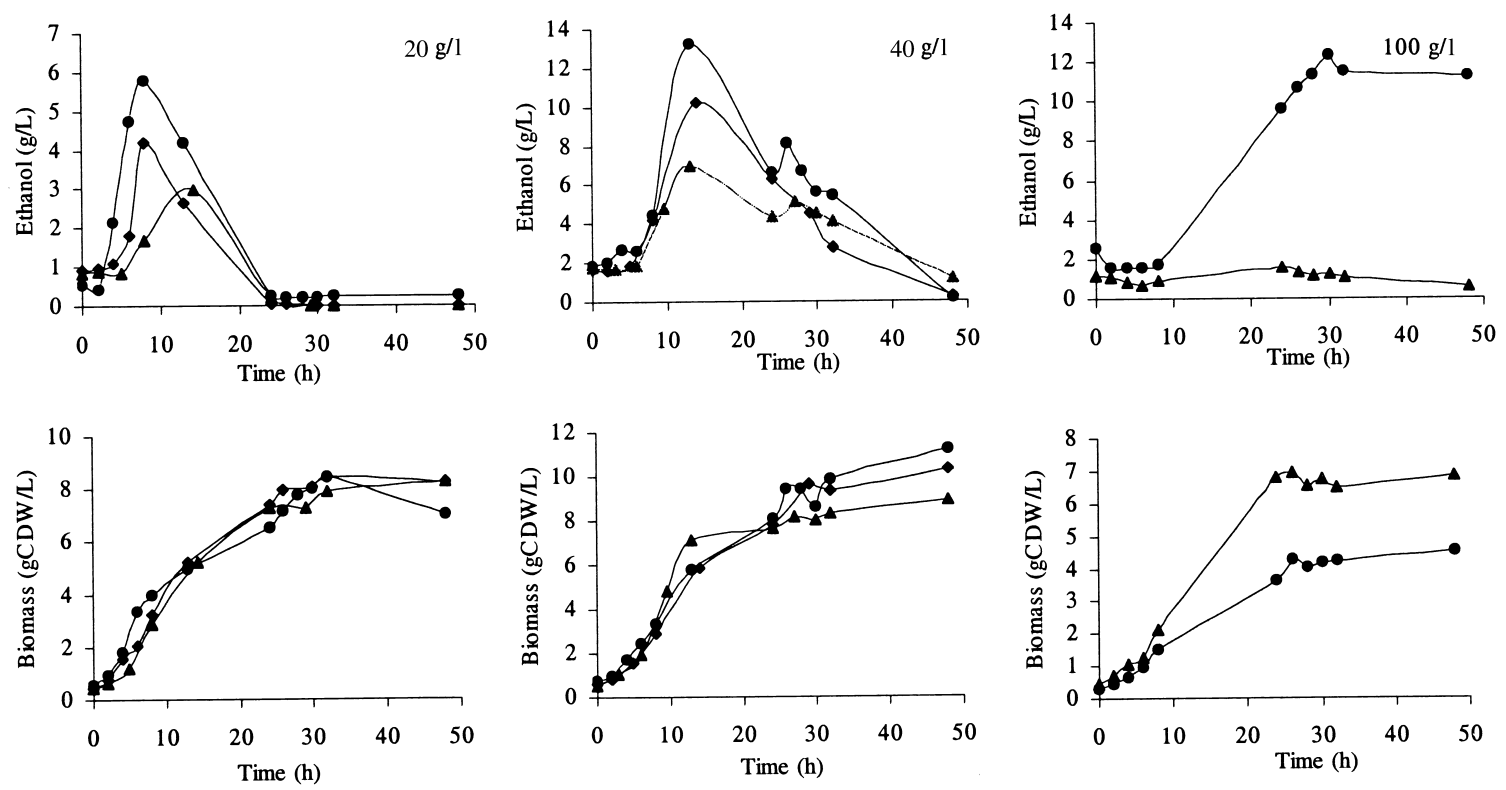

Fig. 2. Effects of air pressure 2 bar $(\bullet), 4$ bar $(\bullet)$, and 6 bar (४), on biomass and ethanol concentrations for different lactose concentrations $20 \mathrm{~g} / \mathrm{l}, 40 \mathrm{~g} / \mathrm{l}$, and $100 \mathrm{~g} / \mathrm{l}$.

\subsection{Pressure effect on "Kluyver-positive" yeast growth}

This yeast, Kluyveromyces marxianus CBS 7894, exhibits a Kluyver effect for lactose and was chosen as a model organism to investigate the application of pressure as a way of enhancing the oxygen transfer rate in the culture. Like the previous yeast, pressure effects on the growth of this yeast were studied. In all experiments, including those without air introduction, a purely oxidative metabolism occurred, and ethanol was never produced, confirming the expected Kluyver-effect.

Preliminary experiments with micro aeration at atmospheric pressure showed that above $20 \mathrm{~g}$ lactose/l, lactose was never consumed completely. To see whether there was enhancement of lactose consumption at higher pressures, two lactose concentrations were used, 10 and $40 \mathrm{~g} / \mathrm{l}$. From Fig. 3 it is possible to infer that pressure increase had a clear positive effect on this yeast metabolism, the biomass production increased and reached its maximal value for an air pressure of 6 bar. A similar behavior was found for the experiments with air bubbling into the culture and 2-bar air pressure. The total fermentation time was reduced from 100 hours, without air introduction, to 30 hours, with pressurized experiments, corresponding to a 3-fold increase in the overall growth rate. Furthermore, a biomass yield of $60 \%$ could be obtained with 6-bar pressure.

For the experiments with $40 \mathrm{~g} / \mathrm{l}$ of lactose (Fig. 4), similar results were obtained. With pressurization, the maximum biomass concentration increased from $4 \mathrm{gCDW} / \mathrm{l}$ (micro aerated) to $14 \mathrm{gCDW} / 1$ (4-bar). Contrarily to the results reported by Castrillo et al. [4], lactose was not totally consumed, probably due to some nutrient limitation. However, the yields were comparable or even better.
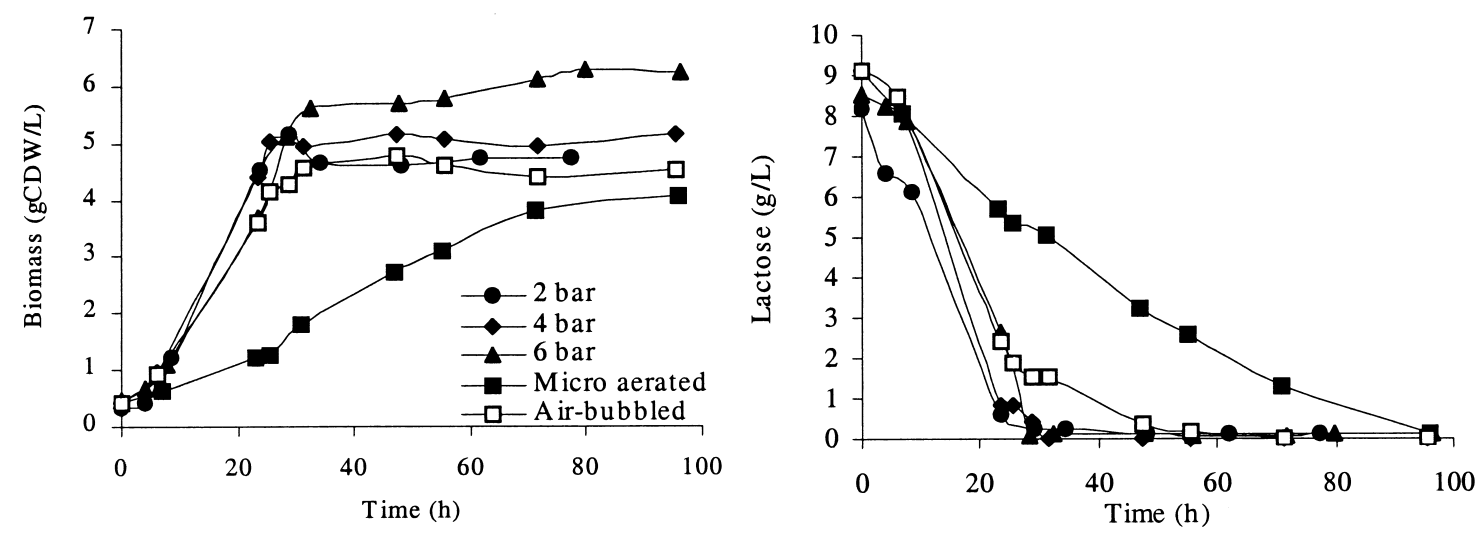

Fig. 3. Growth and lactose consumption profiles of K. marxianus CBS 7894 under different air pressures and with an initial lactose concentration of $10 \mathrm{~g} / \mathrm{l}$. 

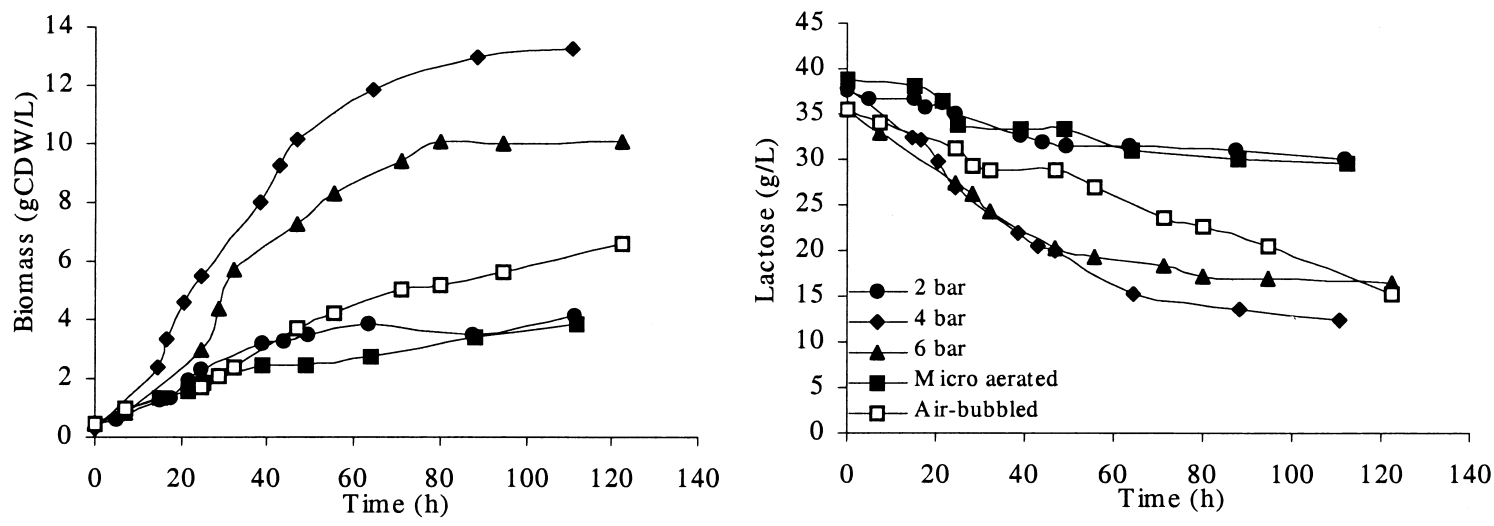

Fig. 4. Growth and lactose consumption profiles of K. marxianus CBS 7894 under different air pressures and with an initial lactose concentration of $40 \mathrm{~g} / \mathrm{l}$.

As is shown in Fig. 5, the ATP formed per gram of biomass is significantly higher (2-fold or more) in the case of micro aeration experiment than in the case of pressurized or stirred experiments. This means a high ATP availability in the former case, for the exponential growth phase (Fig. $3)$. The large difference in specific ATP concentration between pressure ( 4 and 6 bar) and atmospheric experiments, for stationary phase, could be due to the presence of a higher concentration of nonviable cells in the former case. This leads to low ATP concentrations, or to lower maintenance energy needed in the pressurised experiments.

Fig. 6 shows the air pressure effect on biomass yield and productivity. Unlike the previous Kluyveromyces strain, the increase in air pressure had no significant increase in the biomass yield once that main fermentation product is biomass. However, an increase of 4-bar led to a high increase in specific growth rate for both lactose concentrations. Due to the high oxygen transfer rate, the cells have more oxygen in the medium giving higher growth rates, and less time is necessary to obtain maximum cell concentration. It is clear from these results that pressure had no inhibitory effects on the growth of this yeast. At this point it should be remembered that the essential parameter for possible effects of pressure is not the total pressure, but oxygen partial pressure and consequently its concentration in the medium.

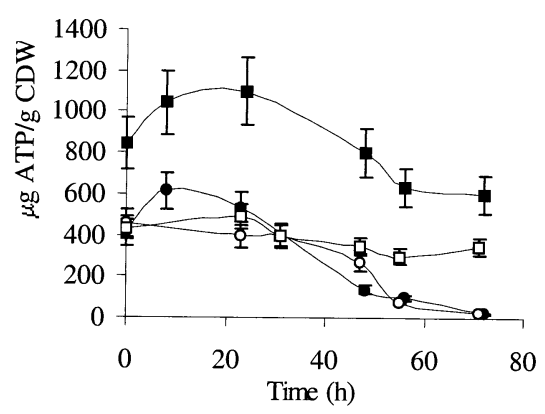

Fig. 5. Effect of air pressure on $\mu \mathrm{g}$ of ATP produced per $\mathrm{g}$ of cell dry weigh produced (biomass) for an initial lactose concentration of $10 \mathrm{~g} / \mathrm{l}: \bigcirc, 4 \mathrm{bar}$; $\boldsymbol{\bullet}, 6$ bar; $\square$, air-bubbled; and $\mathbf{\square}$, micro aerated experiments.
Biomass productivity increased with the increase in oxygen transfer rate. Comparing the experiments with the same OTR (2-bar air pressure and air bubble) it may be seen that pressure gave higher biomass productivity values than for air bubbling. From these results it is possible to infer that the use of pressure had positive effects on the growth rate and productivity of this "Kluyver-positive" yeast. This result is important because the use of pressure to increase oxygen transfer is less expensive than the use of increasing stirring rates.

\subsection{Pressure effect on antioxidant enzyme activities}

To examine the effects of oxygen toxicity on yeast cells, with the increase in oxygen partial pressure, the changes of cellular antioxidant enzyme activities under different air pressures were determined.

For an air pressure of 4-bar, the activities of CuZn-SOD and catalase were at high levels. The same behavior was found for the cellular activity of glutathione reductase, one of the alternative radical scavenging systems $[7,17]$. On the other hand, for further pressure increase, and consequently oxygen radicals generation, high activity levels for the experiment with 6 bar should be expected, which was not the case. The results obtained (Figs. 7 and 8) showed that when Mn-SOD was at a low activity level, catalase and glutathione reductase were at high activity levels. On the contrary, when CuZn-SOD was induced at a high level, the other enzymatic activities decreased. Also, Lee et al. [19] reported that Mn-SOD low activity was compensated by an increase in the amount of catalase and glutathione reductase, when exposed to high concentrations of copper ion in aerobic cultures of Saccharomyces cerevisiae.

These results suggest that there are other stresses than oxygen partial pressure that may be involved in the regulation of these antioxidant enzymes in yeasts. Among these factors are the catabolic repression [9], nutrient limitation [19], heat shock [10], even respiratory adaptation, that can be considered as a stress response [20,21]. Cells have other 

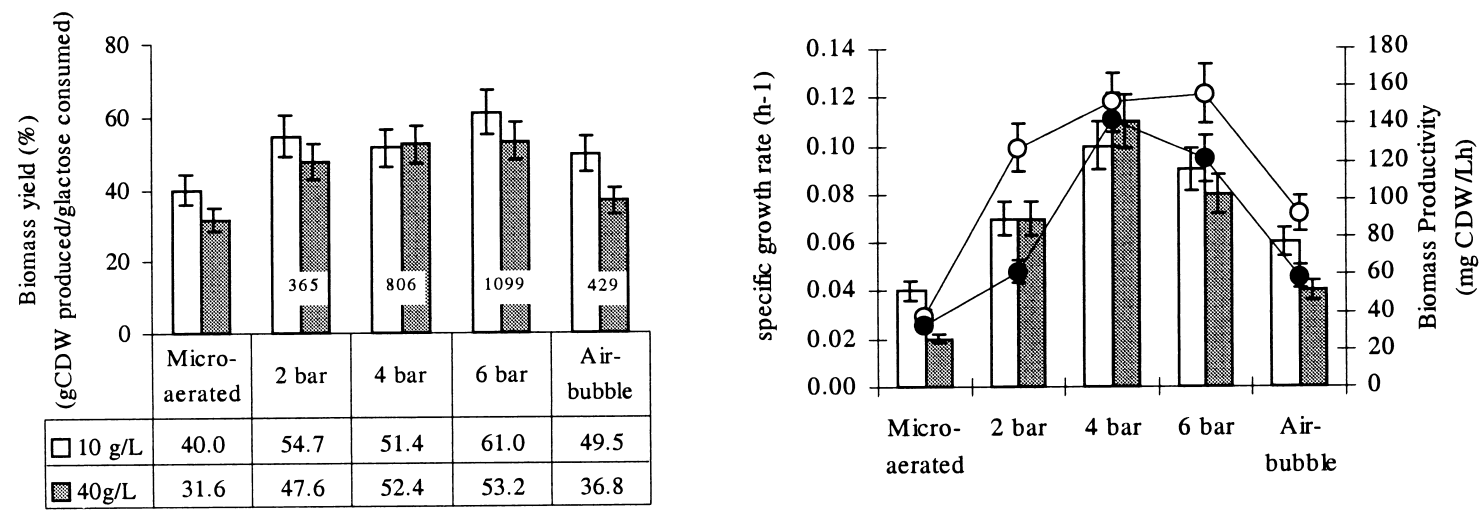

Fig. 6. Effect of air pressure on biomass overall yield (bars), specific growth rate (bars), and productivity $(\bigcirc$ and $\bullet$ ) for an initial lactose concentration of ( $\square$ ) $10 \mathrm{~g} / \mathrm{l}$ and (ם) $40 \mathrm{~g} / \mathrm{l}$. On the first figure, the numbers on bars indicate OTR values expressed in $\mathrm{mg} \mathrm{O}_{2} / \mathrm{lh}$. Productivity was determined by the ratio between $\mathrm{gCDW} / \mathrm{l}$ and the time (h), for the biomass produced after $50 \mathrm{~h}$ of the experiment (maximum biomass).

defensive mechanisms than those studied in this work that protect the cells from oxygen radicals, such as several peroxidases and nonenzymatic species [6].

\section{Conclusions}

In conclusion, it has been demonstrated that the use of air pressure has positive effects on the growth behavior of both Kluyveromyces yeasts and that air pressure may be a way of eliminating oxygen limitation, leading to high biomass productivities.

For K. marxianus ATCC 10022, the air pressure in- creased the biomass yield and decreased the ethanol yield. It was possible to obtain, with a lactose concentration of $20 \mathrm{~g} / 1$ and an air pressure of 6 bar, a biomass yield of $47 \%$ and an ethanol yield of $13 \%$. Ethanol oxidation increased with air pressure. With cultures of $K$. marxianus CBS 7894, it was possible to obtain a biomass yield of $60 \%$ at 6 bar and $10 \mathrm{~g} / \mathrm{l}$ of lactose. Furthermore, a 3 -fold reduction in growth time was achieved. With $40 \mathrm{~g} / \mathrm{l}$, lactose induced a strong inhibitory effect.

The attainment of a $60 \%$ biomass yield for 6 bar and 10 $\mathrm{g} / \mathrm{l}$ of lactose led us to the conclusion that fed-batch cultivation in these conditions will be probably give rise to a very high biomass production.
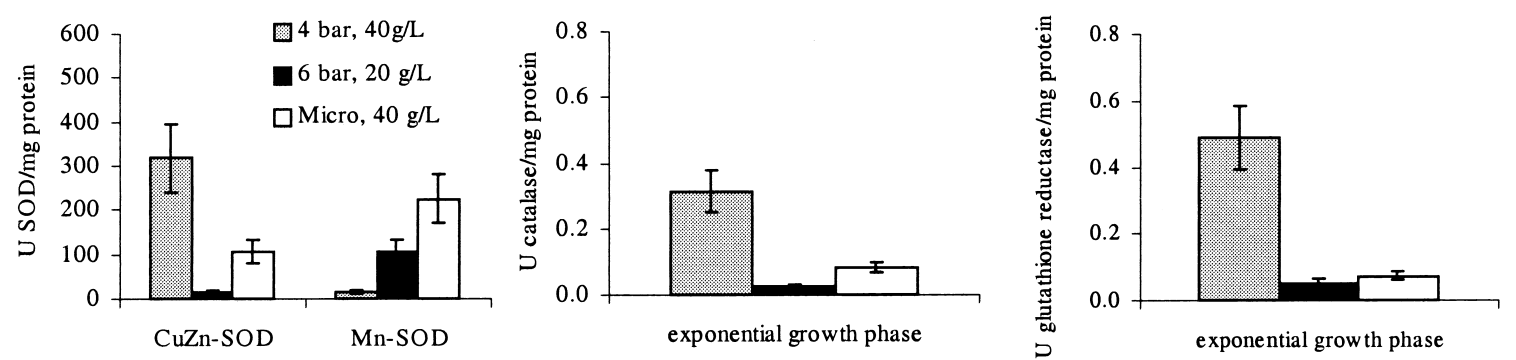

Fig. 7. Cellular activities of mitochondrial (Mn-SOD) and cytosolic (CuZn-SOD) superoxide dismutase, catalase, and glutathione reductase in Kluyveromyces marxianus ATCC 10022, on later exponential growth phase, exposed to different air pressure.
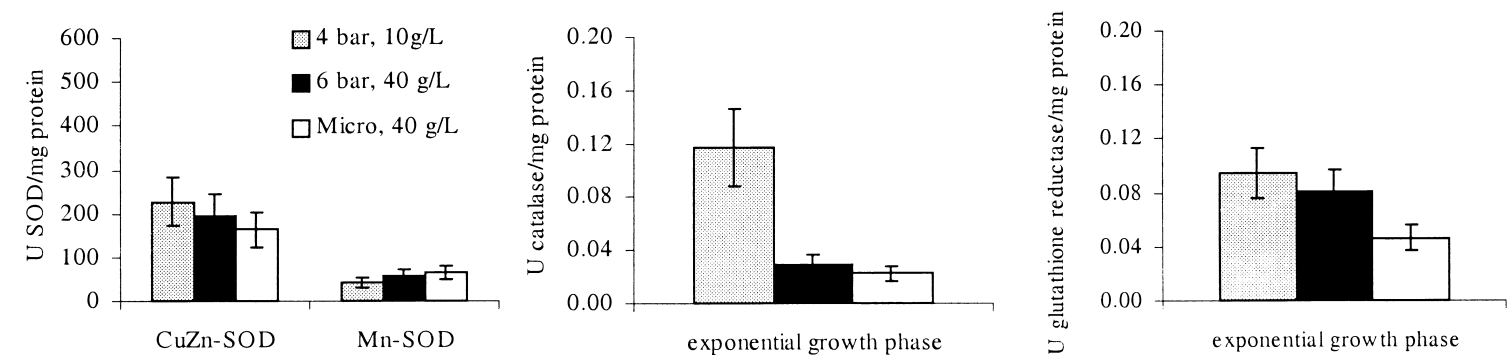

Fig. 8. Cellular activities of mitochondrial (Mn-SOD) and cytosolic (CuZn-SOD) superoxide dismutase, catalase, and glutathione reductase in Kluyveromyces marxianus CBS 7894, on later exponential growth phase, exposed to different air pressure. 
From the results obtained for antioxidant enzymes, it is still unclear whether this difference may be attributable to the increase in the air pressure or to another mechanism. However, because pressure had no inhibitory effects either on growth or on cell metabolism, it can be concluded that the cells could cope with the pressures studied. Further information about the mechanisms involved in oxidative stress response are necessary for a better understanding of the enzymes role.

\section{Acknowledgment}

This work was supported by a $\mathrm{PhD}$ grant from Praxis XXI (Portugal). The authors thank Dr. J.I. Castrillo for the availability of Kluyveromyces marxianus strains.

\section{References}

[1] van Dijken JP, Weusthius RA, Pronk JT. Kinetics of growth and sugar consumption in yeasts. Antonie van Leeuwenhoek 1993;63: $343-52$.

[2] Kiers J, Zeeman AM, Luttik M, et al. Regulation of alcoholic fermentation in batch and chemostat cultures of Kluyveromyces lactis CBS 2359. Yeast 1998;14:459-69.

[3] González Siso MI, Ramil E, Cerdán ME, Freire-Picos MA. Respirofermentative metabolism in Kluyveromyces lactis: ethanol production and the Crabtree effect. Enz Microbiol Technol 1996;18:585-91.

[4] Castrillo JI, Kaliterna J, Weusthuis RA, van Dijken JP, Pronk JT. High-cell-density cultivations of yeasts on disaccharides in oxygen limited batch cultures. Biotechnol Bioeng 1990;49:621-8.

[5] Onken U, Liefke E. Effect of total and partial pressure (oxygen and carbon dioxide) on aerobic microbial processes. Adv Biochem Eng Biotechnol 1990;40:137-69.

[6] Bavouzet JM, Lafforgue-Delorme C., Fonade C, Goma G. The effect of an abrupt stepwise reduction in pressure on the integrity of the eucaryotic and procaryotic cell envelope. Enz Microbiol Technol $1995 ; 17: 712-8$.
[7] Izawa S, Inoue Y, Kimura A. Oxidative stress response in yeast: effect of glutathione on adaptation to hydrogen peroxide stress in Saccharomyces cerevisiae. FEBS Lett 1995;368:73-6.

[8] Gille G, Sigler K. Oxidative stress and living cells. Folia Microbiol 1995;40:131-52.

[9] Galliazzo F, Labble-Bois R. Regulation of CuZn- and Mn-superoxide dismutase transcription in Saccharomyces cerevisiae. FEBS 1993; 315:197-200.

[10] Mager W, Moradas-Ferreira P. Stress response to yeast. Biochem J 1993;290:1-13.

[11] Moradas-Ferreira P, Costa V, Piper P, Mager W. The molecular defenses against reactive oxygen species in yeast. Mol Microbiol 1996;19:651-8.

[12] Miller GL. Use of dinitrosalycilic acid reagent for determination of reducing sugar. Anal Chem 1959;31:426-8.

[13] Siro M-R, Romar H, Lovgren T. Continuous flow method for extraction and bioluminescence assay of ATP in baker's yeast. Eur J App Microbiol Biotechnol 1982;15:258-64.

[14] Bradford MM. A rapid and sensitive method for the quantification of microgram quantities of protein using the principle of protein-dye binding. Anal Biochem 1976;72:248-55.

[15] McCord JM, Fridovich I. Superoxide dismutase: an enzymatic function for erythrocuprein (hemocuprein). J Biol Chem 1969;244:604950 .

[16] Beers RF, Sizer IW. A spectrophotometric method for measuring breakdown of hydrogen peroxide by catalase. J Biol Chem 1952;195: 276-87.

[17] Smith I, Viertheller T, Thorne C. Assay of glutathione reductase in crude tissue homogenates using 5,5'-Dithiobis (2-nitrobenzoic acid). Anal Biochem 1988;175:408-13.

[18] Pinheiro R, Belo I, Mota M. Physiological behaviour of Saccharomyces cerevisiae under increased air and oxygen pressures. Biotechnol Lett 1997;19:703-8.

[19] Lee JK, Kim JM, Kim SW, Nam DH, Yong CS, Huh K. Effect of cooper ion on oxygen damage in superoxide dismutase-deficient Saccharomyces cerevisiae. Arch Pharm Res 1996;19:178-82.

[20] Westerbeek-Marres CAM, Moore MM, Autor AP. Regulation of manganese superoxide dismutase in Saccharomyces cerevisiae: the role of respiratory chain activity. Eur J Biochem 1988;174:611-20.

[21] Clarkson SP, Large PJ, Boulton CA, Bamforth CW. Synthesis of superoxide dismutase, catalase, and other enzymes and oxygen and superoxide toxicity during changes in oxygen concentration in cultures of brewing yeast. Yeast 1991;7:91-103. 